\title{
Commentary and Review on Sacred Geometry
}

\section{Andres J Washington}

Fingerprint Geometric Analysis, Post Office Box 165, Bronx, NY 10451- 0165, USA

*Corresponding author: Andres J Washington, Fingerprint Geometric Analysis, Post Office Box 165, Bronx, NY 10451- 0165, USA, E-mail: director@dermatoglyphics.com

Citation: Andres J Washington (2016) Commentary and Review on Sacred Geometry. J Forensic Sci Criminol 4(5): 504. doi: 10.15744/2348-9804.4.504

Received Date: December 12, 2016 Accepted Date: December 27, 2016 Published Date: December 29, 2016

\begin{abstract}
This formula was designed to discover and analyze the compatibility/incompatibility of individuals and groups of individuals based on fingerprint classifications found in the Henry System of Fingerprint Classification and Filing. In particular, the Primary Classification which depicts the distribution of whorl type patterns across a ten set of fingerprints. A given Primary Classification is therefore examined according to the geometric position that it maintains on a chart of the 1024 classifications. Nevertheless, in order for geometric analysis to be accurate, the dimensions of the Primary Classification Chart must be specific.
\end{abstract}

Keywords: Fingerprints; Fingerprint; Dermatoglyphics; Dermatoglyphic; Demal Ridge Arrangements; Friction Ridge Formations

I have determined that the dimensions of the chart should reflect the perimeter of the base of the Great Pyramid Khufu at Giza Egypt which is 36524 pyramid inches. The chart's dimensions can therefore be described and displayed in any type of units of measurement so long as the perimeter equals 36524 units of measurement. Why is this necessary? Because the Ancient Egyptians show in this number three units of time, 365 for 365 days in a year, 52 for 52 weeks in a year and 24 for the 24 hours in a day. This is considered to be an impossible secret because it is said that today's calendar was not yet developed at the time of the construction of the Great Pyramid. We can also note that 36,524.22 pyramid inches can also be described as the circumference of the Great Pyramid. In essence this equals the number of days in 100 years! In addition, a Tropical Year equals 365.24220 days. The length of each side of the base of the Great Pyramid is 365.2422 Royal Egyptian Cubits.

My thought is that this reflection is appropriate because the Great Pyramid's construction was accurate to begin with.

I must also point out that the numerical values assigned to each digit in the Primary Classification have been adjusted. Digits with a high frequency of whorls are assigned a lower numerical value while digits with low frequency of whorls are assigned a higher numerical value. This would make all primary classifications cohesive in formulation (Figures 1, 2 and 3).

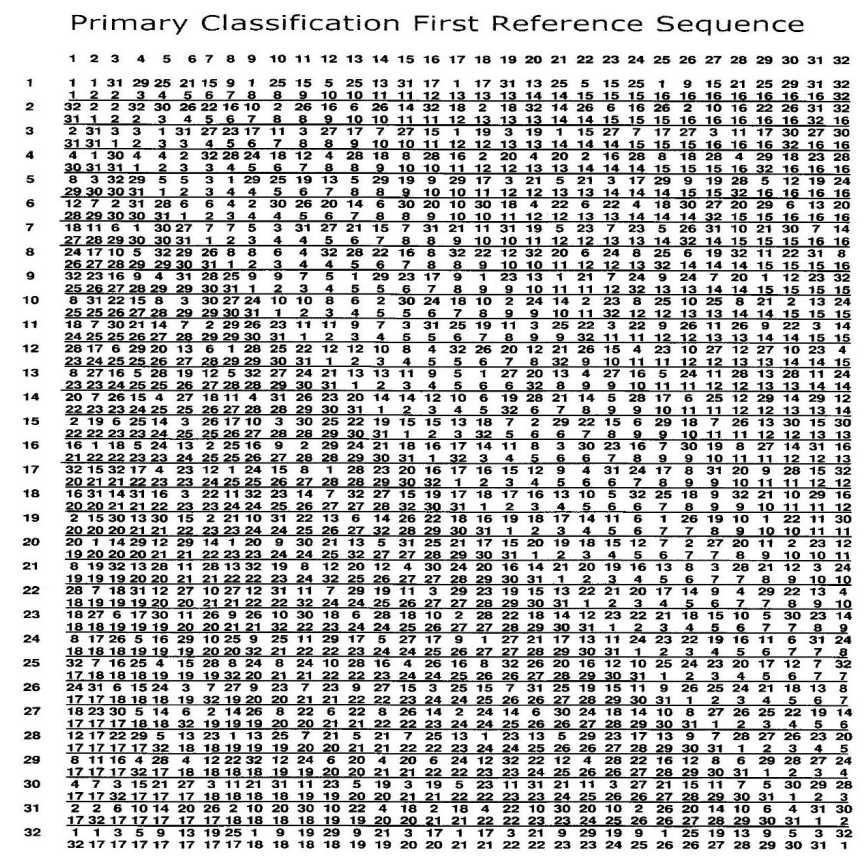

Figure 1: Multi-Sequential Primary Classification Chart 


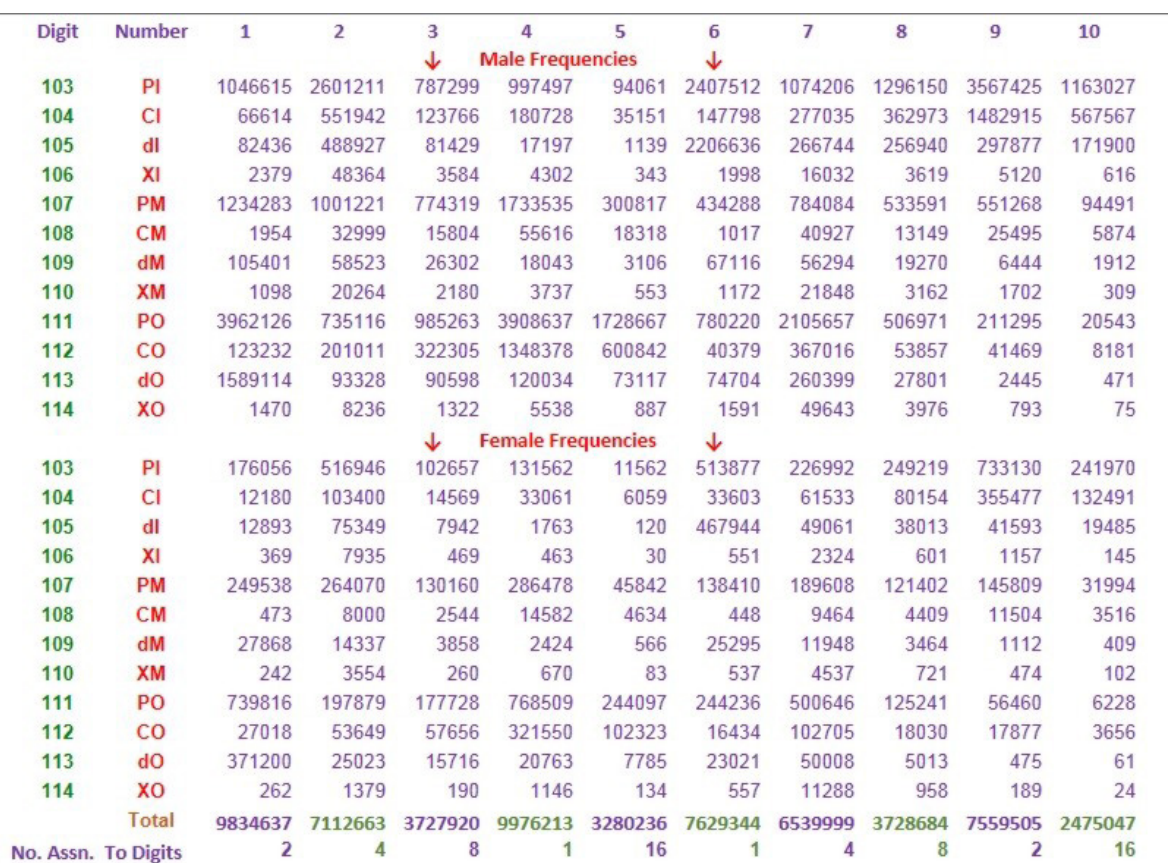

Figure 2: Ten Digit Whorl Frequencies / NCIC FPC Codes: Including 17,951,192 Males and 4,313,521 Females

$$
\begin{aligned}
& \text { Add the value of the right hand digits plus } 1 \text { for consistency } \\
& \text { over the value of the left hand digits plus } 1 \text { for consistency. }
\end{aligned}
$$

\begin{tabular}{|c|c|c|c|c|c|c|c|c|}
\hline & & & & 1 & 2 & 3 & 4 & 5 \\
\hline $\begin{array}{l}\text { The } \\
\text { of }\end{array}$ & $\begin{array}{l}\text { Total } \\
\text { The }\end{array}$ & Value & $\begin{array}{l}\text { Right } \\
\text { Hand +1 }\end{array}$ & 2 & 4 & 8 & 1 & 16 \\
\hline $\begin{array}{l}\text { The } \\
\text { of }\end{array}$ & $\begin{array}{l}\text { Total } \\
\text { The }\end{array}$ & Value & $\begin{array}{l}\text { Left } \\
\text { Hand }+1\end{array}$ & 1 & 4 & 8 & 2 & 16 \\
\hline
\end{tabular}

Figure 3: Numerical Values Assigned to the Ten Digits

There are three perspectives in geometric display, a display on the chart that would be triangular or linear in appearance. And that in this display, Primary Classification codes are Included, Encompassed or Intersected by other codes in the sequence.

\section{References}

1. Henry ER (1900) Classification And Uses of Finger Prints. London: George Routledge And Sons, Limited.

2. Cherrill FR (1954) The Finger Print System at Scotland Yard. London: Her Majesty's Stationery Office.

3. Miyamoto Y (1963) Fingerprints. Japan Publications Trading Company.

4. FBI (1993) Science of Fingerprints: Classification and Uses. Diane Publishing Company.

5. Washington AJ (2016) Sacred Geometry. Forensic Res Criminol Int J 2: 47.

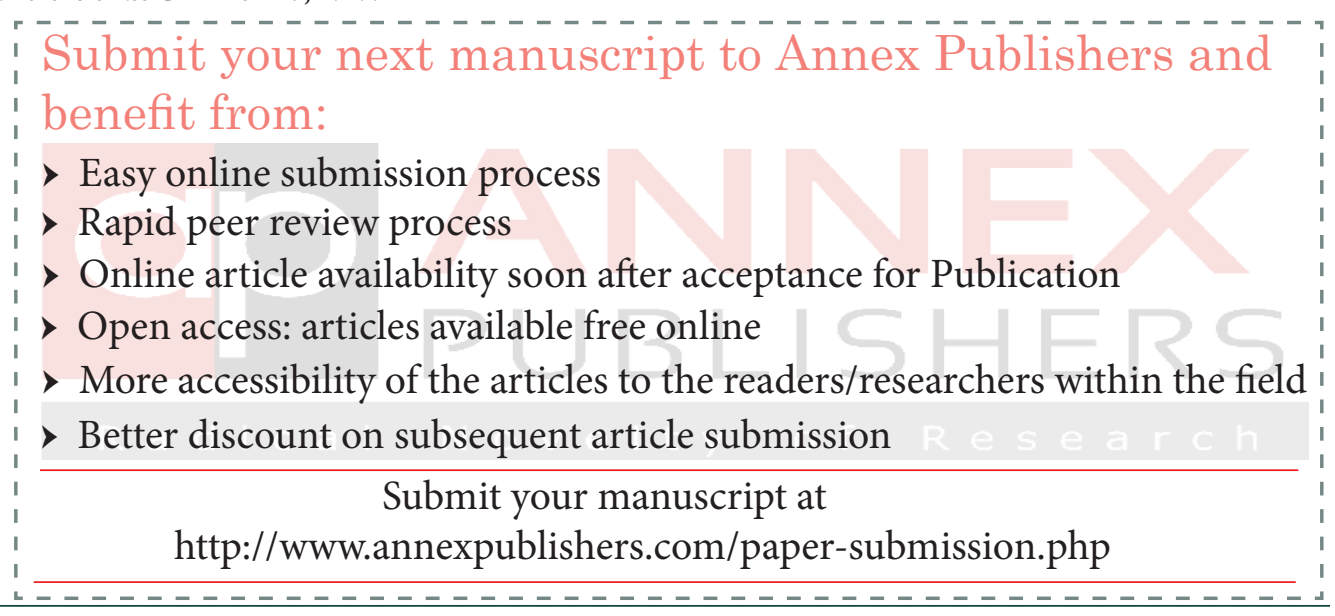

